\title{
The influence of fractionated radiotherapy on the stability of spinal bone metastases: a retrospective analysis from 1047 cases
}

\author{
Tanja Sprave ${ }^{1,3}$, Katharina Hees $^{2}$, Thomas Bruckner ${ }^{2}$, Robert Foerster ${ }^{1,3,4}$, Tilman Bostel ${ }^{1,3}$, Ingmar Schlampp ${ }^{1,3}$,
} Rami El Shafie ${ }^{1,3}$, Nils Henrik Nicolay ${ }^{1,3,5}$, Juergen Debus ${ }^{1,3,5}$ and Harald Rief ${ }^{1,3,5^{*}}$ (D)

\begin{abstract}
Background: The effect of radiotherapy, in particular the application of different multi-fraction schedules in the management of unstable spinal bone metastases (SBM), is incompletely understood. This study aims to compare the radiological response regarding various dose and fractionation schedules of radiotherapy in the palliative treatment of SBM.
\end{abstract}

Methods: We retrospectively assessed 1047 patients with osteolytic SBM, treated with palliative radiotherapy at our department between 2000 and 2015. Lung cancer (40.2\%), breast (16.7\%) and renal cancer (15.2\%) were the most common solid tumors in this study. Different common multi-fraction regimen (5x4Gy, 10x3Gy, 14×2.5Gy and 20x2Gy) were compared with regard to radiological response and recalcification at 3 and 6 months after radiotherapy. The Taneichi score was used for classification of osteolytic SBM.

Results: Median follow up was 6.3 months. The median overall survival (OS) in the short-course radiotherapy (SCR) group using less than 10 treatment fractions was 5.5 months vs. 9.5 months in the long-course radiotherapy (LCR) group using in excess of 10 fractions (log rank $p<.0001$ ). Overall survival (OS) in the SCR group after 3 and 6 months was 66.8 and $49.1 \%$, respectively vs 80.9 and $61.5 \%$, respectively in the LCR group.

$17.6 \%(n=54 / 306)$ and $31.1 \%(n=89 / 286)$ of unstable SBM were classified as stable in the SCR group at 3 and 6 months post radiotherapy, respectively ( $p<.001$ for both). In the LCR group, $24.1 \%(n=28 / 116)$ and $34.2 \%(n=38 / 111)$ of unstable SBM were stabilized after 3 and 6 months, respectively ( $p<.001$ for both).

Conclusions: Our study shows no significant difference in stabilization achieving recalcification rates between multifraction schedules (SCR vs. LCR) in the palliative management of unstable SBM. Both groups with multi-fraction regimen demonstrate a stabilizing effect following 3 and 6 months after radiotherapy.

Keywords: Bone metastases, Stability, Fractionation, Palliative radiotherapy

\section{Background}

Spinal bone metastases occur in up to $40 \%$ of tumor patients during the course of the disease [1].

Associated spine pain, immobility, pathological fractures and neurological deficits substantially reduce the quality of life. Unstable SBMs in particular require coordinated multimodal therapy. In the palliative multidisciplinary

\footnotetext{
* Correspondence: harald.rief@gmx.at

'Department of Radiation Oncology, University Hospital Heidelberg, Im Neuenheimer Feld 400, 69120 Heidelberg, Germany

${ }^{3}$ National Center for Radiation Research in Oncology (NCRO), Heidelberg

Institute for Radiation Oncology (HIRO), Heidelberg, Germany

Full list of author information is available at the end of the article
}

approach, surgical intervention of the cervical and thoracolumbar spinal instability can achieve rapidly improved functional results [2-4]. Less-invasive surgery followed by early adjuvant radiotherapy could be a promising, safe and effective treatment option for achieving solid and durable stability in selected patients without metastatic spinal cord compression (MSCC) [3].

If surgical intervention is not possible, external beam radiotherapy (EBRT) is an established treatment for stabilization in the palliative management of patients with unstable SBM [5-11]. Numerous studies have investigated

(c) The Author(s). 2018 Open Access This article is distributed under the terms of the Creative Commons Attribution 4.0 International License (http://creativecommons.org/licenses/by/4.0/), which permits unrestricted use, distribution, and 
the influence of total dose and fractionation regarding to the pain response [12-23].

However, the optimal total dosage and fractionation in relation to the re-ossification of the unstable SBMs is still unclear. Chow and colleges did not find a significant difference in bone density between 8 Gy in a single fraction and 20 Gy in 5 fractions or 30 Gy in 10 fractions in patients with breast cancer 3 months follow up after irradiation [5]. Reinhold et al. described an increase in bone density over $60 \%$ of lytic vertebral metastases at 3 months after 40 Gy in 20 fractions in subgroup with 13 participants [6].

We initiated this retrospective mono-centric analysis to investigate the influence of different fractionation schemes and doses on the re-ossification rate in metastatic solid cancers. To the best of our knowledge, no comparable study has been described in the literature so far.

\section{Methods}

\section{Assessment of the radiological response}

From 2000 to 2015, 1047 patients with histologically confirmed solid tumors and osteolytic SBM were treated with external beam RT (EBRT) at our department. Patient data were taken from the cancer registry of the National Center for Tumor Diseases (Heidelberg, Germany). SBM were diagnosed using computed tomography $(\mathrm{CT})$ and magnetic resonance imaging (MRI).

The stability of osteolytic SBM was examined according to the Taneichi score [24] based on the CT imaging before EBRT and at 3 and 6 months after treatment. This score classified osteolytic SBM as "stable" or "unstable" by definition of risk factors such as tumor size and the degree of costovertebral joint destruction for the thoracic region (Th 1 to 10) and tumor size and the degree of pedicle destruction for the lumbar segments (Th 11 to L5). Osteolytic metastases were rated on a scale from A to G, whereby subtypes $\mathrm{A}$ to $\mathrm{C}$ were defined as stable, and subtypes $\mathrm{D}$ to $\mathrm{G}$ as unstable. In cases with multiple metastases in which only one lesion was detected as unstable, the Taneichi score was defined as unstable.

After 3 and 6 months, 621 and 590 cases were evaluated in the SCR group vs. 205 and 197 cases in the LCR group, respectively. The initial classification of the osseous metastases into stable or unstable was made by experienced radiologists based on CT imaging. Subsequent evaluation was performed after 3 and 6 months using the baseline imaging, the changes in bone density, and the extent of the stabilizing resclerosing of the osteolytic lesions.

Bone density in irradiated vertebral bodies was assessed at baseline and at 3 and 6 months after RT. Bone density was assessed with the Syngo Osteo CT workstation in manually selected regions of interest (ROIs). Hounsfield units (HU) were used for bone density measurements. Siemens Somatom Sensation Open (Siemens, Erlangen, Germany) was used for all CT examinations. Measurements were carried out at the appropriate site by a single physician.

This study was approved by the independent ethics committee of the Heidelberg Ethics Committee on 22 October 2012 (\# S-513/2012). Due the retrospective design, informed consent was not required. This retrospective study analyzes/utilizes the cumulative patient data taken from previously published studies, which also evaluated the influence of multi-fraction radiotherapy on the stability of osteolytic SBM, but employed entirely different aspects $[7,10,25,26]$.

\section{Statistical analysis}

The empirical distribution of continuous variables is described by the number of observations, mean and standard deviation; scores were described by median and range, the description of categorical variables includes the number and percentage of patients belonging to the relevant categories. Possible differences between the group of patients with $<=10$ fractions compared to those with $>10$ fractions were evaluated with t-test for continuous data, with Mann-Whitney U-test for ordinal data (scores) and with chi-square-test for categorical data. Multivariate analysis was performed using binary logistic regression. This analysis evaluates possible prognostic factors of baseline stability, namely age, gender, KPS, primary site, localization and number and type of metastasis, calculated separately for patients with SCR or LCR.

"Bone survival" (BS) was defined as the time from initial diagnosis of SBM until death. The time of site irradiation was not equal to the time of initial diagnosis of SBM. Overall survival (OS) was defined as time from the beginning of RT until death. We estimated patient survival using the Kaplan-Meier method. Patients were censored on the basis of whether or not they were alive. Possible differences were reported with $p$-values of the log-rank tests. All statistical analyses were done using the SAS software version 9.4 (SAS Institute, Cary, NC, USA).

\section{Patient's characteristics}

Palliative EBRT was required for analgesia in 53.9\% $(n=564)$, stabilizing intention in $42.6 \%(n=446)$ and for neurological deficits in $2.2 \% \quad(n=23)$. Only 14 patients $(1,3 \%)$ had adjuvant irradiation after prior surgical intervention.

Thus, 534 cases (51\%) were classified as unstable SBM, and a stabilizing orthopedic corset was indicated in 475 cases (45.4\%). Because the Taneichi score application is limited to thoracic and lumbar spine segments, in this study the most SBM were consequently localized in $60.7 \%(n=635)$, in the thoracic spine and in lumbar spine $39.2 \%(n=410)$.

Patients' mean age at diagnosis of SBM was 63.1 years (SD +/- 11.1 years), and median Karnofsky performance 
status (KPS) was $80.0 \%$ (range 30-100) [27]. Gender was well balanced with 578 male (55.2\%) and 469 female patients (44.8\%).The most frequent tumor type was non-small cell lung cancer (NSCLC) with 40.6\% $(n=425)$, followed by breast cancer $16.7 \%(n=175)$ and renal cancer $15.2 \%(n=159)$. Antiresoptive treatment such as bisphosphonate or denosumab was received by $62.6 \%$ participants. The characteristics of all participants included in this analysis are summarized in Table 1.

\section{Radiotherapy}

After virtual simulation, RT was performed as irradiation of the involved vertebral body as well as the vertebrae immediately above and below using $6 \mathrm{MV}$ individually-formed beams after CT-scan based 3D-planning. Palliative radiotherapy was delivered in most cases with $10 \times 3 \mathrm{~Gy}(72.3 \%$; $n=757), 20 \times 2$ Gy $(17.6 \% ; n=184), 14 \times 2.5$ Gy $(8.8 \% ; n=$ $92)$ and other individual doses $(1.4 \% ; n=15)$. The therapy schedule was prescribed according to general performance status, histology of primary solid tumor, prognosis and life expectancy.

Two multi-fraction groups was formed: patients who received shot course radiotherapy (SCR) with $</=10$ fractions vs. patients undergoing long course radiotherapy (LCR) $>10$ fraction.

\section{Results}

Median follow-up time for both groups was 6.3 months (range 0.03-283 months).

Initially, 51\% $(n=534)$ of 1047 SBM were classified as unstable SBM, of which 377 were in the SCR and 157 in the LCR group.

After 3 months, 621 with SCR and 205 patients with LCR could be re-examined, the originally unstable SBM were reclassified as stable in $17.6 \%(54 / 306)$ of the cases for the SCR group vs. 24.1\% (28/116) for the LCR group (McNemar's test $p<.001$ ). After 6 months, 590 with SCR and 197 patients with LCR could be re-examined, and $31.1 \%$ of initially unstable SBM $(89 / 286)$ were classified as stable in the SCR group vs $34.2 \%$ (38/111) for the LCS group. The frequent reasons for lost of follow up were worsening of the condition, continuation of therapy in other clinics or death.

Conversely, in the SCR group at 3 and 6 months follow RT $1.6 \%(5 / 315)$ and $2.0 \%(6 / 304)$ of the stable SBM were reclassified as unstable. A numerically comparable destabilizing rate was also found in the LCR group after 3 and 6 months respectively 4.5\% (4/89) and 7\% (6/86) (Table 2).

The median overall survival (OS) in the SCR group was 5.5 months vs. 9.5 months in the LCR (log rank $p<.0001)$. The OS in the SCR group after 3 and 6 months was 66.8 and $49.1 \%$, respectively vs 80.9 and $61.5 \%$, respectively in the LCR group (Fig. 1). The stability dependent OS analysis showed no significant difference either for both groups or separately (log rank test for both groups: $p=0.631$, SCR: $p=0.181$ and LCR $p=0.946$ ). At the last follow-up, 3.8\% $(n=26)$ patients were still alive in the SCR group vs. $6.1 \%(n=17)$ in the LCR group (chi square test $p=0.049$ ).

The median bone survival (BS) in SCR group was 6.7 months vs. 12.2 months in the LCR group (log rank $p<.0001$ ). (Fig. 2).

Gender had no influence on stabilization rate in both groups. SCR was delivered in 769 cases $(73.4 \%)$ vs. LCR in 278 cases $(26.6 \%)$. Antiresoptive treatment was prescribed to $62.6 \%$ of all patients, $66.7 \%$ in the SCR collective vs. $51.1 \%$ in the LCR group (chi square test $p<0.001$ ).

The univariate analysis within the SCR group showed a significant difference in KPS between stable and unstable SBM (Mann-Whitney U-test, $p=0.027$ ). Multivariate analysis in the SCR group showed a significant association between multiple metastases and instability (logistic regression, $p<0.0001$ ) (Table 3 ).

The univariate analysis within the LCR group found a significant relationship between age and unstable SBM (Mann-Whitney U-test, $p=0.034$ ). Multivariate analysis in this group showed a significant association between pulmonary metastases and instability (logistic regression, $p<0.013$ ) (Table 3).

\section{Discussion}

This retrospective study compared radiological response by various dose and fractionation schedules of radiotherapy in the palliative treatment of SBM. All multi-fraction schedules showed a stabilizing effect, and there was stabilization observed both in the SCR and LCR groups. We determined a statistically significant stabilizing effect after 3 and 6 months within each group $(p<.0001)$. There was no difference between the groups.

There are few relevant studies that investigate the impact of fractionation on remineralization, but not stabilization of lytic bone lesions. The available data show a great heterogeneity of the primary endpoints and patient collective. Therefore, our results are difficult to compare with other studies.

The reossification of osteolysis as a surrogate for radiotherapeutic response has been widely investigated and integrated into daily routine. However, the relevant studies show very contradictory results. A prospective study by Chow et al. was conducted to examine the feasibility of the evaluation based on CT exams, the remineralization of the osteolytic bone lesions at 3 months after palliative radiotherapy. Radiotherapy was applied with 8 Gy in a single fraction vs. 20 Gy in 5 fractions or 30 Gy in 10 fractions. Of 25 breast cancer participants, 11 patients suffered from osteolytic vertebral bone metastasis. Bisphosphonate therapy was allowed. At the 3 months follow up no significant change of the 
Table 1 Demographics

\begin{tabular}{|c|c|c|c|c|c|}
\hline$<=10$ fractions & & & & & $p$-value \\
\hline$n=769$ & & & & & \\
\hline$\%$ & $n$ & $\%$ & $n$ & $\%$ & \\
\hline
\end{tabular}

Age (years)

Mean (SD)

$63.3+/-10.7$

$62.5+/-12.0$

$63.1+/-11.1$

$0.330^{a}$

Gender

Male

Female

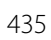

334

56.6

43.4

$80(40-100)$

$80(30-100)$

51.4

578

55.2

$0.141^{b}$

Karnofsky-index

Median (range)

Primary site

NSCLC

Breast cancer

Renal cancer

Other

$\begin{array}{ll}356 & 46.3 \\ 106 & 13.8 \\ 88 & 11.4 \\ 219 & 28.5\end{array}$

Localization of metastases

Cervical

Thoracic

Lumbar

1

460

308

0.1

59.8

40.1

Number of metastases

Mean (SD)

$2.6+/-2.1$

350

419

45.5

54.5

Other distant metastases

Liver
Brain
Lung
Tissue

20326

112

26.4

14.6

24.1

7.2

66.7

57.9

51.0

49.0

45.9

$69 \quad 248$

24.8

24.8

25.5

24.8

0.3

63.0

36.7

102

$2.9+/-2.8$

136

142

48.9

51.1

21.6

10.8

$$
26.6
$$

4.3

51.1

52.4

43.5

56.5

43.9
469

44.8

$80(30-100)$

$0.696^{c}$

$<0.001^{\mathrm{b}}$

$0.476^{b}$

2

635

$425 \quad 40.6$

$175 \quad 16.7$

$159 \quad 15.2$

288

27.5

0.2

60.7

410

39.1

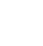

$0.329^{b}$

$2.7+/-2.3$

$0.069^{a}$

$486 \quad 46.4$

$561 \quad 53.6$

3.6

$263 \quad 25.1$

$0.112^{b}$

$142 \quad 13.6$

$0.119^{b}$

259

$0.396^{b}$

67

$0.097^{b}$

655

$<0.001^{\mathrm{b}}$

590

$0.112^{b}$

513

$0.033^{b}$

534

$0.562^{b}$
Antiresoptive treatment

Chemotherapy

Stable metastases

Unstable metastases

Orthopedic corset

513

445

392

377

Radiotherapy schedule

$$
\begin{aligned}
& 1 \times 8 \text { Gy } \\
& 5 \times 4 \text { Gy } \\
& 10 \times 3 \text { Gy } \\
& 11 \times 3 \text { Gy } \\
& 12 \times 3 \text { Gy } \\
& 14 \times 2.5 \text { Gy } \\
& 20 \times 2 \text { Gy }
\end{aligned}
$$

Baseline characteristics of participants. Explanation: Others: colon cancer, neuroendocrine cancer, prostata cancer, ovarian cancer, urothelial cancer, uterine cancer, vulva cancer. Abbreviation: NSCLC non-small-cell lung carcinoma; ${ }^{a}$ t-test; ${ }^{b}$ chi-square-test, ${ }^{c}$ u-test

median \% bone density was assessed. There was no further description of the lytic metastases with regard to stability prior and after irradiation [5].
In contrast, Koswig and Budach showed a significant difference in recalcification of the osteolytic bone metastasis in favor of the fractionated group in a randomized 
Table 2 Stability after 3 and 6 months in both groups

\begin{tabular}{|c|c|c|c|c|c|c|}
\hline \multirow[t]{3}{*}{$<=10$ fractions } & \multicolumn{4}{|c|}{3 months } & \multirow{2}{*}{\multicolumn{2}{|c|}{ Total }} \\
\hline & Unstable & & Stable & & & \\
\hline & $n$ & $\%$ & $n$ & $\%$ & $n$ & $\%$ \\
\hline Unstable & 252 & 82.4 & 54 & 17.6 & 306 & 49.3 \\
\hline \multirow[t]{2}{*}{ Stable } & 5 & 1.6 & 310 & 98.4 & 315 & 50.7 \\
\hline & & & & & 621 & 100 \\
\hline \multicolumn{7}{|l|}{$>10$ fractions } \\
\hline Unstable & 88 & 75.9 & 28 & 24.1 & 116 & 56.6 \\
\hline \multirow[t]{2}{*}{ Stable } & 4 & 4.5 & 85 & 95.5 & 89 & 43.4 \\
\hline & & & & & 205 & 100 \\
\hline \multirow[t]{6}{*}{$<=10$ fractions } & & 6 months & & & & \\
\hline & Unstable & & Stable & & Total & \\
\hline & $n$ & $\%$ & $n$ & $\%$ & $n$ & $\%$ \\
\hline & 197 & 68.9 & 89 & 31.1 & 286 & 48.5 \\
\hline & 6 & 2.0 & 298 & 98.0 & 304 & 51.5 \\
\hline & & & & & 590 & 100 \\
\hline \multicolumn{7}{|l|}{$>10$ fractions } \\
\hline Unstable & 73 & 65.8 & 38 & 34.2 & 111 & 56.4 \\
\hline \multirow[t]{2}{*}{ Stable } & 6 & 7.0 & 80 & 93.0 & 86 & 43.7 \\
\hline & & & & & 197 & 100 \\
\hline
\end{tabular}

two-arm $(1 \times 8$ Gy vs. $10 \times 3$ Gy) trial. In the multi-fraction group, a significant effect was assessed only in patients with breast cancer $(p<0.001)$. No information on stability was provided [8].

In line with above mentioned previous study, Wachenfeld et al. assessed in 14 patients with vertebral bone lesions of breast cancer different radiological response of the irradiated bone varies depending on the form of metastasis. Accordingly, osteolytic metastases generally showed an increase in CT density to approximately $150 \%$ of the initial value at 3 months after the multi-fraction irradiation. This effect was further enhanced by additional chemotherapy [28]. Two decades later, we showed similar results in a retrospective analysis of 115 patients with 135 spinal metastases from the breast cancer. In contrast, no correlation between differences in the bone density and simultaneous chemotherapy was observed [7].

Notably, different fractionation showed no difference in the recalcification rates of multiple myeloma bone lesions [29]. The randomized trial by Rudzianskiene et al. was conducted to compare two schedules $(1 \times 8$ Gy vs. $10 \times 3 \mathrm{~Gy})$ in palliative treatment of multiple myeloma lesions. The recalcification was measured in both groups 4 and 12 weeks follow irradiation. Remineralization occurred in 32/101 patients (33.7\%), of which 17 (53.2\%) were complete and 15 (46.2\%) partial. No differences in reossification were observed between $1 \times 8$ Gy vs. $10 \times 3$ Gy schedules [29].

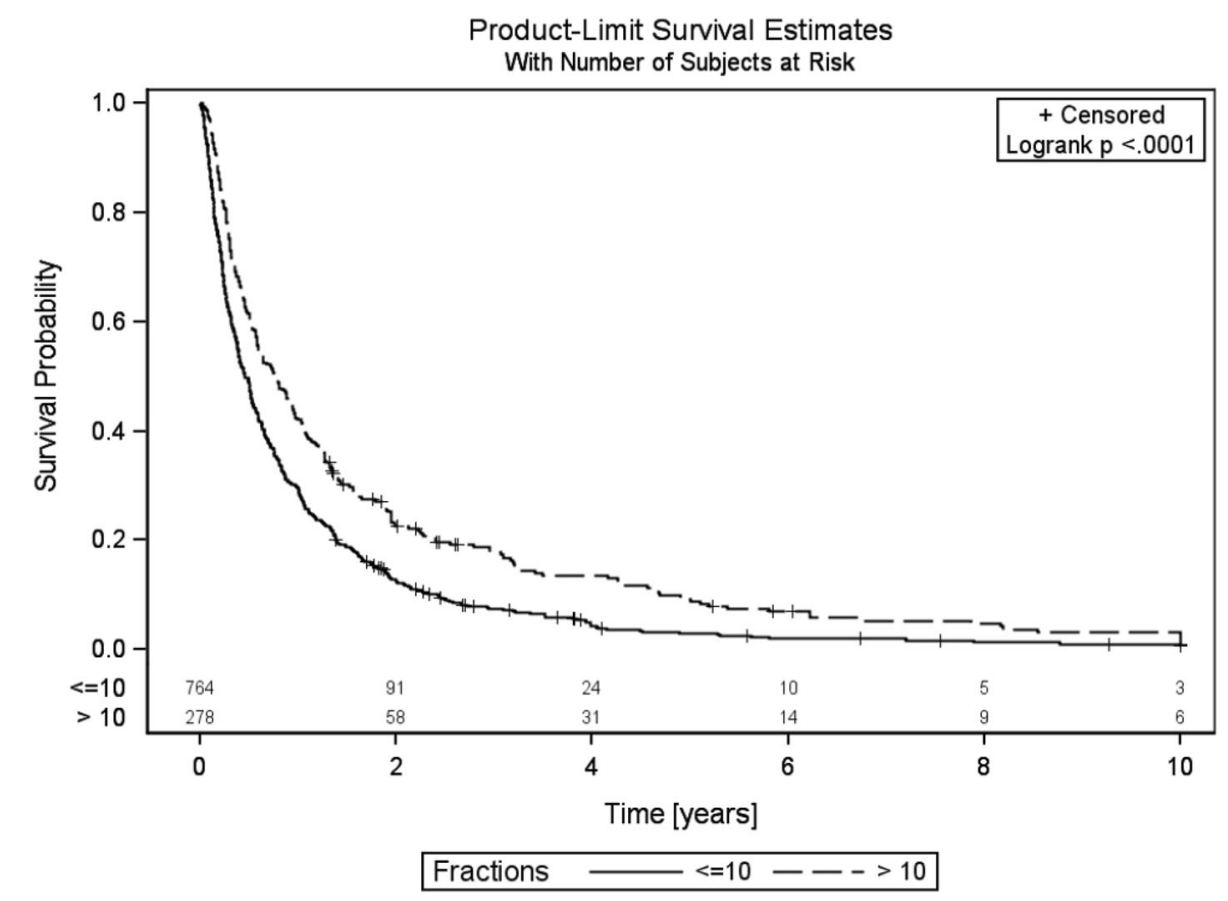

Fig. 1 Overall survival of both arms, time in years 


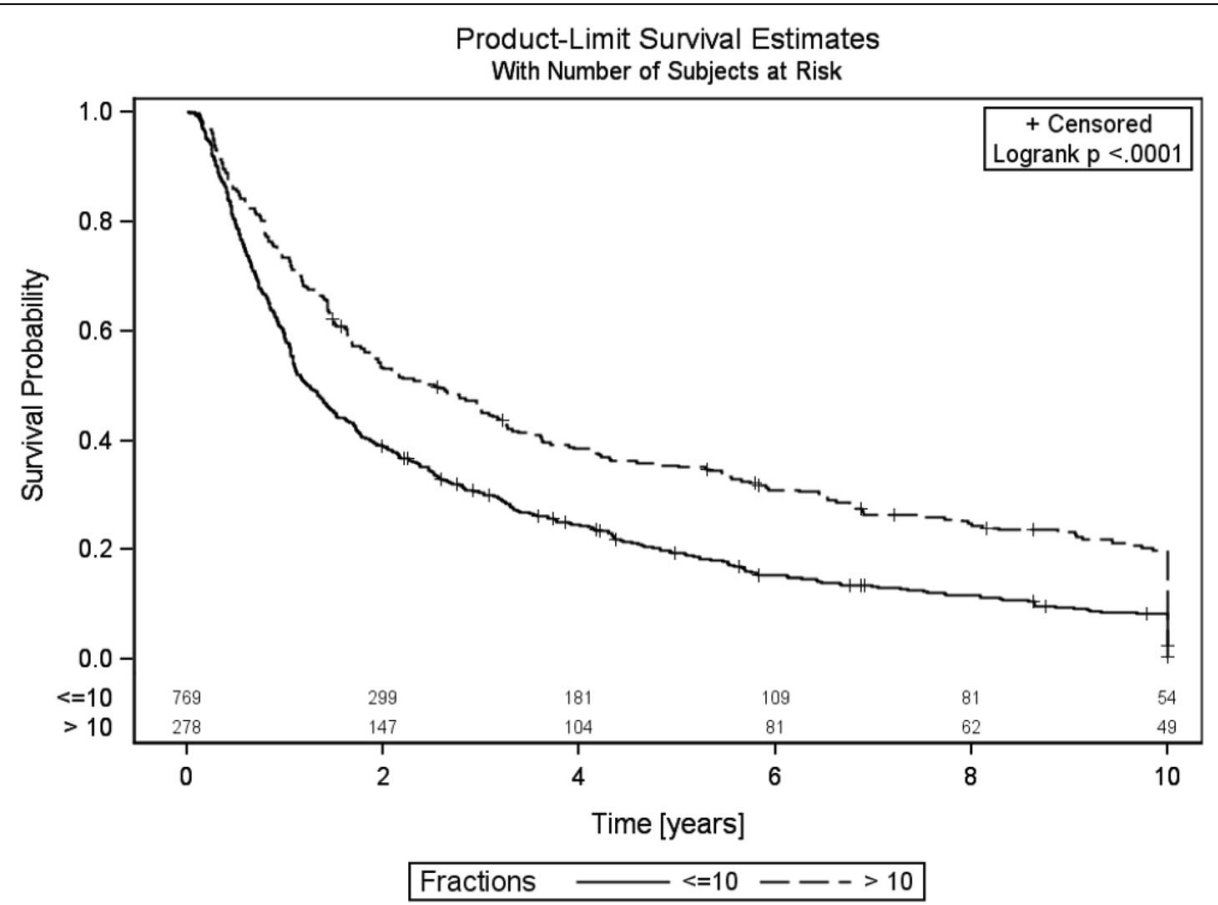

Fig. 2 Bone survival of both arms, time in years

The systematic review by Groenen estimated the impact of EBRT in stabilizing metastatic bone lesions, in particular the effect the radiotherapy alone and combined with bisphosphonates or RANK ligands (RANKL). The emphasis of this study was placed on biomechanical characteristics such as bone quality changes and pathological fractures. It was concluded that no sufficient evidence exist, which demonstrate the positive influence of the EBRT on bone density and pathological fracture respective [30]. The incidence of pathological fractures in all patients in our study at baseline and 6 months was moderate by 7.4 and $9 \%$ respectively [31]. None of the relevant studies provided information on the influence of fractionation on the stability of osseous metastases.

Despite the lack of evidence, our results confirm the clinical experience that radiotherapy is an effective local treatment for unstable SBM from solid tumors. To the best of our knowledge, this was the largest retrospective study to date investigating the influence of various multi-fraction palliative radiotherapy regimen on the stability of SBM. A consequence of this findings a prospective randomized study was initiated in our department to investigate the influence of different palliative multi-fraction schemata on the bone density of vertebral metastases [32].

In our cohort $62.6 \%$ of patients received antiresoptive treatment. In comparison with our results, Udagawa and co-worker reported higher rates of bone-target therapy with $69 \%(n=103)$ of 149 patients with untreated bronchial carcinoma and osseous metastases [33]. Another study reported even higher rates with $89 \%$ in patients with advanced breast cancer and osseous metastases [34]. In group comparison, the prescription of antiresoptive treatment in our trial was significant higher with $66.7 \%$ vs $51.1 \%$ in the SCR group $(p<0.001)$. These findings may reflect a realization of palliative therapeutic approaches, especially rapid pain relief by shorter life expectancy. This difference in our study cannot be explained. Multicentric international comparisons of prescription patterns of antiresoptive treatment would be necessary.

Statistically, the median OS and BS was significantly better in the LCR group $(9.5 ; 12.2$ and $5.5 ; 6.7)$ months respectively, $(\log$ rank $p<.0001)$. Stability did not impact OS in either group. Statistically, a significant percentage of patients was alive in LRT group at the time of the survey, which indirectly reflects the common practice, particularly the influence of subjective life expectancy estimation (KPS, extra osseous disease extent) on the choice of multi-fraction regime by radio-oncologists.

Although the strengths of our investigation include the representative large collective and standardized evaluation of bone density and stability of all osteolytic lesions, several limitations must be acknowledged. In addition to a retrospective character and the unequal number of patients in the comparative groups (SRT > LRT). 
Table 3 Univariate and multivariate analysis in both groups

\begin{tabular}{|c|c|c|c|c|c|c|}
\hline & \multicolumn{6}{|c|}{$<=10$ fractions } \\
\hline & \multirow{2}{*}{\multicolumn{2}{|c|}{$\begin{array}{l}\text { stable } \\
n=377\end{array}$}} & \multirow{2}{*}{\multicolumn{2}{|c|}{$\frac{\text { instable }}{n=392}$}} & \multirow[t]{3}{*}{$p$-value } & \multirow[t]{3}{*}{$p$-value (logistic Regression) } \\
\hline & & & & & & \\
\hline & $n$ & $\%$ & $n$ & $\%$ & & \\
\hline \multicolumn{7}{|l|}{ Age (years) } \\
\hline Mean (SD) & \multicolumn{2}{|l|}{$62.6+/-10.4$} & \multicolumn{2}{|l|}{$64.0+/-11.0$} & $0.084^{a}$ & 0.214 \\
\hline \multicolumn{7}{|l|}{ Gender } \\
\hline Male & 219 & 55.9 & 216 & 57.3 & \multirow[t]{2}{*}{$0.690^{\mathrm{a}}$} & \multirow[t]{2}{*}{0.742} \\
\hline Female & 173 & 44.1 & 161 & 42.7 & & \\
\hline \multicolumn{7}{|l|}{ Karnofsky- Index } \\
\hline Median (range) & \multicolumn{2}{|l|}{$80(40,100)$} & \multicolumn{2}{|l|}{$70(40,100)$} & $0.027^{c}$ & 0.090 \\
\hline \multicolumn{5}{|l|}{ Primary site } & \multirow[t]{5}{*}{$0.933^{b}$} & \multirow[t]{5}{*}{0.883} \\
\hline NSCLC & 183 & 46.7 & 173 & 45.9 & & \\
\hline Breast cancer & 55 & 14.0 & 51 & 13.5 & & \\
\hline Renal cancer & 42 & 10.7 & 46 & 12.2 & & \\
\hline Other & 112 & 28.6 & 107 & 28.4 & & \\
\hline \multicolumn{5}{|l|}{ Localization metastases } & \multirow[t]{3}{*}{$0.303^{b}$} & \multirow[t]{3}{*}{0.637} \\
\hline Cervical/Thoracic & 228 & 58.2 & 233 & 61.8 & & \\
\hline Lumbar & 164 & 41.8 & 144 & 38.2 & & \\
\hline \multicolumn{5}{|l|}{ Number metastases } & \multirow[t]{3}{*}{$<0.0001^{b}$} & \multirow[t]{3}{*}{$<0.0001$} \\
\hline Solitary & 210 & 53.6 & 140 & 37.1 & & \\
\hline Multiple & 182 & 46.4 & 237 & 62.9 & & \\
\hline Other distant metastases & & & & & & \\
\hline Liver & 102 & 26.0 & 101 & 26.8 & $0.809^{b}$ & 0.518 \\
\hline Brain & 59 & 15.1 & 53 & 14.1 & $0.697^{b}$ & 0.759 \\
\hline Lung & 95 & 24.2 & 90 & 23.9 & $0.907^{b}$ & 0.902 \\
\hline Tissue & 35 & 8.9 & 20 & 5.3 & $0.051^{b}$ & 0.120 \\
\hline & $>10$ fractions & & & & & \\
\hline & stable & & instable & & $p$-value & p-value (log. Regression) \\
\hline & $n=121$ & & $n=157$ & & & \\
\hline & $n$ & $\%$ & $n$ & $\%$ & & \\
\hline Age (years) & & & & & & \\
\hline Mean (SD) & $60.7+/-12.7$ & & $63.8+/-11.3$ & & $0.034^{a}$ & 0.168 \\
\hline Gender & & & & & & \\
\hline Male & 60 & 49.6 & 83 & 52.9 & $0.588^{\mathrm{a}}$ & 0.643 \\
\hline Female & 61 & 50.4 & 74 & 47.1 & & \\
\hline Karnofsky- Index & & & & & & \\
\hline Median (range) & $80(40,100)$ & & $70(30,100)$ & & $0.063^{c}$ & 0.079 \\
\hline Primary site & & & & & $0.575^{b}$ & 0.933 \\
\hline NSCLC & 28 & 23.1 & 41 & 26.1 & & \\
\hline Breast cancer & 28 & 23.1 & 41 & 26.1 & & \\
\hline Renal cancer & 30 & 24.8 & 41 & 26.1 & & \\
\hline Other & 35 & 28.9 & 34 & 21.7 & & \\
\hline Localization metastases & & & & & $0.687^{b}$ & 0.970 \\
\hline Cervical/Thoracic & 75 & 62.0 & 101 & 64.3 & & \\
\hline
\end{tabular}


Table 3 Univariate and multivariate analysis in both groups (Continued)

\begin{tabular}{|c|c|c|c|c|c|c|}
\hline & \multicolumn{6}{|c|}{$<=10$ fractions } \\
\hline & \multirow{2}{*}{\multicolumn{2}{|c|}{$\begin{array}{l}\text { stable } \\
n=377\end{array}$}} & \multirow{2}{*}{\multicolumn{2}{|c|}{$\begin{array}{l}\text { instable } \\
n=392\end{array}$}} & \multirow[t]{3}{*}{$p$-value } & \multirow[t]{3}{*}{$p$-value (logistic Regression) } \\
\hline & & & & & & \\
\hline & $n$ & $\%$ & $n$ & $\%$ & & \\
\hline Lumbar & 46 & 38.0 & 56 & 35.7 & & \\
\hline Number metastases & & & & & $0.662^{b}$ & 0.834 \\
\hline Solitary & 61 & 50.4 & 75 & 47.8 & & \\
\hline Multiple & 60 & 49.6 & 82 & 52.2 & & \\
\hline Other distant metasta & & & & & & \\
\hline Liver & 32 & 26.6 & 28 & 17.8 & $0.084^{b}$ & 0.965 \\
\hline Brain & 17 & 14.1 & 13 & 8.3 & $0.129^{b}$ & 0.274 \\
\hline Lung & 45 & 37.2 & 29 & 18.5 & $<0.001^{\mathrm{b}}$ & 0.013 \\
\hline Tissue & 8 & 6.6 & 4 & 2.6 & $0.098^{b}$ & 0.406 \\
\hline
\end{tabular}

Abbreviation: ${ }^{\mathrm{a}}$-test; ${ }^{\mathrm{b}}$ chi-square-test, ${ }^{\mathrm{c} u \text {-test }}$

\section{Conclusion}

Our study demonstrated no significant difference in recalcification rates between various multi-fraction schedules (SCR vs. LCR) in the palliative management of unstable SBM. Use of shorter, equally potent schemata may shorten hospitalization, increase the patients' quality of life and save resources.

\section{Abbreviations}

BS: Bone survival; CT: Computer tomography; CTV: Clinical target volume; EBRT: External beam radiotherapy; GTV: Gross tumor volume; Gy: Gray; KPS: Karnofsky performance status; LCR: Long course radiotherapy; OS: Overall survival; PTV: Planning target volume; RANKL: Receptor activator of nuclear factor kappa-B ligand; ROI: Region of interest; SBM: Spinal bone metastasis; SCR: Short course radiotherapy

\section{Acknowledgements}

We thank the German Bone Cancer Research Group Members for their great effort.

\section{Availability of data and materials}

The data used in this analysis are from publications available in the public domain.

\section{Authors' contributions}

TS and HR developed and planned this trial. $\mathrm{KH}$ and TB are responsible for statistical considerations/basis of the analysis. RES, RF, TB, IS, HR, NHN and JD estimated the treatment of bone metastases. All authors read and approved the final manuscript

\section{Ethics approval and consent to participate}

The Independent Ethics Committee of Heidelberg University 22 October 2012 (\# S-513/2012).

\section{Consent for publication}

Not applicable.

\section{Competing interests}

The authors declare that they have no competing interests.

\section{Publisher's Note}

Springer Nature remains neutral with regard to jurisdictional claims in published maps and institutional affiliations.

\section{Author details}

${ }^{1}$ Department of Radiation Oncology, University Hospital Heidelberg, Im Neuenheimer Feld 400, 69120 Heidelberg, Germany. ${ }^{2}$ Department of Medical Biometry, University Hospital Heidelberg, Im Neuenheimer Feld 130.3, 69120 Heidelberg, Germany. ${ }^{3}$ National Center for Radiation Research in Oncology (NCRO), Heidelberg Institute for Radiation Oncology (HIRO), Heidelberg, Germany. ${ }^{4}$ Department of Radiation Oncology, University Hospital Zurich, Raemistrasse 100, 8091 Zurich, Switzerland. ${ }^{5}$ German Cancer Research Center (DKFZ), Clinical Cooperation Unit Radiation Oncology, Im Neuenheimer Feld 280, 69120 Heidelberg, Germany.

Received: 20 November 2017 Accepted: 18 July 2018

Published online: 24 July 2018

\section{References}

1. Wong DA, Fornasier VL, MacNab I. Spinal metastases: the obvious, the occult, and the impostors. Spine. 1990;15(1):1-4.

2. Wu X, Ye Z, Pu F, Chen S, Wang B, Zhang Z, Yang C, Yang S, Shao Z. Palliative surgery in treating painful metastases of the upper cervical spine: case report and review of the literature. Medicine. 2016;95(18):e3558.

3. Bernard F, Lemee JM, Lucas O, Menei P. Postoperative quality-of-life assessment in patients with spine metastases treated with long-segment pedicle-screw fixation. J Neurosurg Spine. 2017;26(6):725-35.

4. Klimo P Jr, Schmidt MH. Surgical management of spinal metastases. Oncologist. 2004;9(2):188-96.

5. Chow E, Holden L, Rubenstein J, Christakis M, Sixel K, Vidmar M, Finkelstein J, Hayter C, Loblaw A, Wong R, et al. Computed tomography $(C T)$ evaluation of breast cancer patients with osteolytic bone metastases undergoing palliative radiotherapy--a feasibility study. Radiother Oncol. 2004;70(3):291-4.

6. Reinbold R-D, Wannemacher M, Hodapp N, Adler C-P. Osteodensitometry of vertebral metastases after radiotherapy using quantitave computed tomography. Skelet Radiol. 1989;18:517-21.

7. Foerster R, Eisele C, Bruckner T, Bostel T, Schlampp I, Wolf R, Debus J, Rief H. Bone density as a marker for local response to radiotherapy of spinal bone metastases in women with breast cancer: a retrospective analysis. Radiat Oncol. 2015;10:62

8. Koswig S, Budach V. Remineralization and pain relief in bone metastases after after different radiotherapy fractions (10 times 3 Gy vs. 1 time 8 Gy). A prospective study. Strahlenther Onkol. 1999;175(10):500-8.

9. Schlampp I, Rieken S, Habermehl D, Bruckner T, Forster R, Debus J, Rief $H$. Stability of spinal bone metastases in breast cancer after radiotherapy: a retrospective analysis of 157 cases. Strahlenther Onkol. 2014;190(9):792-7.

10. Wolf RJ, Foerster R, Bruckner T, Bostel T, Schlampp I, Debus J, Rief H, Group GB. Survival and prognostic factors in patients with stable and unstable spinal bone metastases from solid tumors: a retrospective analysis of 915 cases. BMC Cancer. 2016;16:528. 
11. Harada H, Katagiri H, Kamata M, Yoshioka Y, Asakura H, Hashimoto T, Furutani K, Takahashi M, Sakahara H, Nishimura T. Radiological response and clinical outcome in patients with femoral bone metastases after radiotherapy. J Radiat Res. 2010;51(2):131-6.

12. Foro Arnalot P, Fontanals AV, Galceran JC, Lynd F, Latiesas XS, de Dios NR, Castillejo AR, Bassols ML, Galan JL, Conejo IM, et al. Randomized clinical trial with two palliative radiotherapy regimens in painful bone metastases: $30 \mathrm{~Gy}$ in 10 fractions compared with $8 \mathrm{~Gy}$ in single fraction. Radiother Oncol. 2008;89(2):150-5.

13. Guckenberger M, Mantel F, Gerszten PC, Flickinger JC, Sahgal A, Letourneau D, Grills IS, Jawad M, Fahim DK, Shin JH, et al. Safety and efficacy of stereotactic body radiotherapy as primary treatment for vertebral metastases: a multi-institutional analysis. Radiat Oncol. 2014:9:226.

14. Gutierrez Bayard L, Salas Buzon Mdel C, Angulo Pain E, de Ingunza Baron L. Radiation therapy for the management of painful bone metastases: results from a randomized trial. Rep Pract Oncol Radiother. 2014;19(6):405-11.

15. Hartsell WF, Scott CB, Bruner DW, Scarantino CW, Ivker RA, Roach M 3rd, Suh JH, Demas WF, Movsas B, Petersen IA, et al. Randomized trial of shortversus long-course radiotherapy for palliation of painful bone metastases. J Natl Cancer Inst. 2005;97(11):798-804.

16. Hoskin P, Rojas A, Fidarova E, Jalali R, Mena Merino A, Poitevin A, Oucrif S, Abdelwahab S, Kochbati L, Plieskiene A, et al. IAEA randomised trial of optimal single dose radiotherapy in the treatment of painful bone metastases. Radiother Oncol. 2015;116(1):10-4.

17. Kaasa S, Brenne E, Lund JA, Fayers P, Falkmer U, Holmberg M, Lagerlund M, Bruland $\mathrm{O}$. Prospective randomised multicenter trial on single fraction radiotherapy ( 8 Gy $x$ 1) versus multiple fractions (3 Gy x 10) in the treatment of painful bone metastases. Radiother Oncol. 2006;79(3):278-84.

18. Kougioumtzopoulou A, Zygogianni A, Liakouli Z, Kypraiou E, Kouloulias V. The role of radiotherapy in bone metastases: a critical review of current literature. Eur J Cancer Care (Engl). 2017;26(6). https://doi.org/10.1111/ecc. 12724

19. Lutz S, Berk L, Chang E, Chow E, Hahn C, Hoskin P, Howell D, Konski A, Kachnic L, Lo S, et al. Palliative radiotherapy for bone metastases: an ASTRO evidence-based guideline. Int J Radiat Oncol Biol Phys. 2011;79(4):965-76.

20. McQuay HJ, Collins SL, Carroll D, Moore RA. Radiotherapy for the palliation of painful bone metastases. Cochrane Database Syst Rev. 2000;2:Cd001793.

21. Nielsen OS, Bentzen SM, Sandberg E, Gadeberg CC, Timothy AR Randomized trial of single dose versus fractionated palliative radiotherapy of bone metastases. Radiother Oncol. 1998;47(3):233-40.

22. Niewald M, Tkocz HJ, Abel U, Scheib T, Walter K, Nieder C, Schnabel K, Berberich W, Kubale R, Fuchs M. Rapid course radiation therapy vs. more standard treatment: a randomized trial for bone metastases. Int J Radiat Oncol Biol Phys. 1996;36(5):1085-9.

23. Wu JS, Wong RK, Lloyd NS, Johnston M, Bezjak A, Whelan T, Supportive Care Guidelines Group of Cancer Care O. Radiotherapy fractionation for the palliation of uncomplicated painful bone metastases - an evidence-based practice guideline. BMC cancer. 2004:4:71.

24. Taneichi H, Kaneda K, Takeda N, Abumi K, Satoh S. Risk factors and probability of vertebral body collapse in metastases of the thoracic and lumbar spine. Spine. 1997;22(3):239-45.

25. Foerster R, Habermehl D, Bruckner T, Bostel T, Schlampp I, Welzel T, Debus J, Rief H. Spinal bone metastases in gynecologic malignancies: a retrospective analysis of stability, prognostic factors and survival. Radiat Oncol. 2014;9:194.

26. Rief $\mathrm{H}$, Bischof M, Bruckner T, Welzel T, Askoxylakis V, Rieken S, Lindel K, Combs S, Debus J. The $s$ of osseous metastases of the spine in lung cancer--a retrospective analysis of 338 cases. Radiat Oncol. 2013;8(1):200.

27. Yates JW, Chalmer B, McKegney FP. Evaluation of patients with advanced cancer using the Karnofsky performance status. Cancer. 1980;45(8):2220-4.

28. Wachenfeld I, Sanner G, Bottcher HD, Kollath J. The remineralization of the vertebral metastases of breast carcinoma after radiotherapy. Strahlenther Onkol. 1996;172(6):332-41.

29. Rudzianskiene M, Inciura A, Gerbutavicius R, Rudzianskas V, Macas A, Simoliuniene R, Dambrauskiene R, Kiavialaitis GE, Juozaityte E. Single vs. multiple fraction regimens for palliative radiotherapy treatment of multiple myeloma: $A$ prospective randomised study. Strahlenther Onkol. 2017;193(9):742-9.

30. Groenen $\mathrm{KH}$, Pouw MH, Hannink G, Hosman AJ, van der Linden YM, Verdonschot N, Tanck E. The effect of radiotherapy, and radiotherapy combined with bisphosphonates or RANK ligand inhibitors on bone quality in bone metastases. A systematic review. Radiother Oncol. 2016;119(2):194-201.
31. Rief H, Förster R, Rieken S, Bruckner T, Schlampp I, Bostel T, Debus J. The influence of orthopedic corsets on the incidence of pathological fracture in patients with spinal bone metastases after radiotherapy. BMC Cancer. 2015; 15:745.

32. Sprave T, Welte SE, Bruckner T, Förster R, Bostel T, Schlampp I, Nicolay NH, Debus J, Rief H. Intensity-modulated radiotherapy with integrated-boost in patients with bone metastasis of the spine: study protocol for a randomized controlled trial. Trials. 2018;19(1):59.

33. Udagawa H, Niho S, Kirita K, Umemura S, Matsumoto S, Yoh K, Goto K. Impact of denosumab use on the survival of untreated non-squamous nonsmall cell lung cancer patients with bone metastases. J Cancer Res Clin Oncol. 2017;143(6):1075-82.

34. Schröder J, Fietz T, Köhler A, Petersen $V$, Tesch $H$, Spring L, Fleitz A, Jänicke M, Marschner N, TMK-group (tumour registry breast Cancer). Treatment and pattern of bone metastases in 1094 patients with advanced breast cancerresults from the prospective German tumour registry breast Cancer cohort study. Eur J Cancer. 2017:79:139-48.
Ready to submit your research? Choose BMC and benefit from:

- fast, convenient online submission

- thorough peer review by experienced researchers in your field

- rapid publication on acceptance

- support for research data, including large and complex data types

- gold Open Access which fosters wider collaboration and increased citations

- maximum visibility for your research: over $100 \mathrm{M}$ website views per year

At BMC, research is always in progress.

Learn more biomedcentral.com/submissions 